\title{
A dinâmica transmídia de fake news conforme a concepção pragmática de verdade
}

\section{The transmedia dynamics of fake news}

by the pragmatic conception of truth

GEANE CARVALHO A L Z M ORA a

Universidade Federal de Minas Gerais, Programa de Pós-Graduação em Comunicação Social. Belo Horizonte MG, Brasil

LUCIA NA A N D R D E b

Universidade Federal de Minas Gerais, Programa de Pós-Graduação em Comunicação Social. Belo Horizonte MG, Brasil

\section{RESUMO}

A propagação de notícias falsas sobre o julgamento do ex-presidente Luiz Inácio Lula da Silva, em janeiro de 2018, é aqui examinada conforme a concepção pragmática de verdade proposta por Charles Sanders Peirce (1839-1914). Por meio de coleta em redes sociais on-line, observou-se esforço coletivo para fixação de crenças concorrentes, conforme os métodos peirceanos de tenacidade e autoridade. O processo comunicacional analisado, caracterizado como ativismo transmídia, foi impulsionado pela mediação de hashtags que remetiam à polarização política e pelos posts atribuídos a celebridades. Concluise que a disputa pelo valor semiótico da verdade fomentou a expansão transmídia de conteúdos falsos e, paradoxalmente, de notícias verificadas.

Palavras-chave: Transmídia, semiose, notícias falsas

\section{ABSTRACT}

The spreading of fake news about the trial of former president Luiz Inácio Lula da Silva on January, 2018 is examined here according to the pragmatic conception of truth proposed by Charles Sanders Peirce (1839-1914). Through collecting in online social networks, the collective effort to establish competing beliefs was observed, according to Peircean methods of tenacity and authority. The communicational process analyzed, characterized as transmedia activism, was driven by the mediation of hashtags that referred to political polarization and the posts attributed to celebrities. It is concluded that the dispute for the semiotic value of truth fostered the transmedia expansion of fake content and, paradoxically, verified news.

Keywords: Transmedia, semiosis, fake news

a Doutora em Comunicação e Semiótica pela Pontifícia Universidade Católica de São Paulo (PUC-SP), em 2005, professora da Universidade Federal de Minas Gerais (UFMG). Orcid: https://orcid. org/0000-0003-2994-8308. E-mail: geanealzamora@ ufmg.br

${ }^{\mathrm{b}}$ Doutora em Comunicação Social pela UFMG, pesquisadora do Centro de Convergência de Novas Mídias (CCNM/ UFMG) e do Núcleo de Pesquisa em Conexões Intermidiáticas (NucCon/UFMG). Orcid: https://orcid.org/00000002-6740-9463. E-mail: lucianadrade@gmail.com 


\section{INTRODUÇÃO}

D AKE NEWS, OU notícia falsa, foi considerada a palavra do ano em - 2017 pela editora britânica Collins. Segundo informações da edito2017). Levantamento realizado pela empresa norte-americana de mídia digital BuzzFeed aponta que as cinquenta notícias falsas que mais geraram engajamento no Facebook em 2017 alcançaram 23,5 milhões de ações (como reações por emoji, comentários e compartilhamentos), cerca de dois milhões a mais que em 2016. O levantamento revela ainda que os principais temas relacionados a notícias falsas são crimes, política e saúde. Além disso, confirma o Facebook como ambiente midiático privilegiado para circulação de notícias falsas (Silverman, Lytvynenko, \& Pham, 2017).

Mas, afinal, o que é fake news e por que elas geram tamanho engajamento? Allcott e Gentzkow (2017) definem notícias falsas como artigos noticiosos que são intencionalmente e verificavelmente falsos, embora capazes de enganar os leitores. Para os autores, o crescimento do engajamento em redes sociais on-line, associado ao declínio da confiança em veículos tradicionais de informação, explica o vertiginoso crescimento da propagação de notícias falsas. Eles ressaltam, porém, que a circulação desse tipo de conteúdo não é novidade, e apresentam vários exemplos antigos de notícias falsas, como é o caso do jornal norte-americano New York Sun, que em 1835 publicou uma série de reportagens sobre a descoberta de vida na lua. Teorias de conspiração com implicações políticas permeiam, segundo eles, a longa história de fake news nos Estados Unidos.

De acordo com Wardle e Derakhshan (2017), fake news é uma designação inadequada para descrever o complexo fenômeno da poluição da informação, ou desordem da informação, além de ter sido apropriada por políticos de todo o mundo para designar notícias que lhes são desagradáveis. Por causa disso, os autores optam pelo termo desinformação para descrever o fenômeno, o qual não se restringe à imprensa, a partir de sete classificações: falsa conexão (legendas que não correspondem ao conteúdo), falso contexto, manipulação do contexto, sátira ou paródia (sem intencionalidade explícita), conteúdo enganoso (uso equivocado de dados), conteúdo impostor (uso de fontes falsas) e conteúdo fabricado (com intenção de manipular a opinião pública e prejudicar).

No Brasil, este é um tema de grande preocupação. Segundo relatório produzido em 2017 pela empresa canadense de pesquisa de opinião pública GlobeScan para a BBC, o Brasil é o país mais preocupado com notícias falsas no mundo (BBC, 2017). Entretanto, tal preocupação não evita a propagação desse tipo de notícia. Cerca de doze milhões de brasileiros difundem conteúdo noticioso falso ou distorcido sobre política nas redes sociais on-line, de acordo com levantamento do 
Grupo de Pesquisa em Políticas Públicas para o Acesso à Informação (GPOPAI) da Universidade de São Paulo (USP). Realizado em junho de 2017, a partir do monitoramento de conteúdo político falso ou distorcido em quinhentas páginas digitais, o relatório sublinha o alcance colossal dessas notícias, considerando a média de duzentos seguidores por usuário (Martins, 2017).

A dinâmica de circulação de tais publicações, fortemente ancorada em ações de compartilhamento, é aqui investigada no âmbito do pragmatismo peirceano, também chamado pragmaticismo (Peirce Edition Project, 1998). Essa vertente teórica, proposta por Charles Sanders Peirce no final do século XIX, examina a formação de hábitos em relação à fixação de crenças e ao ideal da verdade, aspectos muito relevantes na compreensão do engajamento social que impulsiona a circulação contemporânea de conteúdos noticiosos falsos ou distorcidos. $\mathrm{O}$ processo é aqui caracterizado como ativismo transmídia. Ancorado em sólido sistema de crenças que delineia hábitos de ação em conexões on-line/off-line, o ativismo transmídia visa à formação de certa opinião como efeito prático da informação disseminada.

\section{A CONCEPÇÃO PRAGMÁTICA DE VERDADE}

É a crença que delineia a formação da opinião, não a verdade. Tal concepção, de viés pragmático, evidencia que verdade não é atributo necessário da notícia. Essa compreensão permeia os estudos da notícia há muito tempo e é de suma importância para a compreensão do fenômeno contemporâneo das notícias falsas. Em meados do século XIX, o escritor francês Honoré de Balzac já afirmava, como um dos axiomas de sua Monografia da imprensa parisiense, que "para o jornalista, tudo o que é provável é verdadeiro" (Balzac, 1991, p. 164). $\mathrm{Na}$ visão de Balzac, a imprensa preza a crença, não a verdade.

Em Opinião pública, lançado em 1922, Walter Lippmann adverte que notícia e verdade devem ser claramente distinguidas, argumentando que a função da notícia é sinalizar um evento e a função da verdade é trazer luz aos fatos escondidos, pô-los em relação. Ele propõe o conceito de pseudoambiente para descrever as representações da realidade, como é o caso das notícias, às quais o comportamento humano responde. O pseudoambiente se organiza em torno de crenças, não de verdades, pois "o que acreditamos ser uma imagem verdadeira, nós a tratamos como se ela fosse o próprio ambiente" (Lippmann, 2008, p. 22). Lippmann confere valor pragmático ao pseudoambiente, no qual transitam imagens estereotipadas da realidade, porque as crenças que este suscita delineiam "nossos sentimentos, pensamentos e ações" (p. 37). Ou seja, o valor pragmático do pseudoambiente está relacionado ao efeito prático das crenças que suscita. 


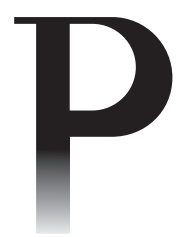

${ }^{1}$ Peirce é considerado o precursor do pragmatismo, movimento filosófico que investiga a relação entre pensamento e ação. $\mathrm{O}$ movimento surgiu nos primeiros anos da década de 1870, em Cambridge (Estados Unidos), a partir de um pequeno grupo de estudiosos de filosofia, entre eles Charles Sanders Peirce e William James. Nessa época, Peirce cunhou a máxima pragmática, segundo a qual o significado de qualquer conceito é a soma total de suas consequências práticas concebíveis. A diversidade de interpretações acerca dessa máxima levou Peirce a nomear, por volta de 1905, de pragmaticismo sua perspectiva pragmática com o intuito de diferenciá-la das demais. Dentre os aspectos diferenciadores, destacam-se a ênfase no significado e não na verdade, no hábito (social) e não na experiência (individual), no falibilismo e na autocorreção contínua. Sobre o assunto ver Ketner e Kloeser(1986).

${ }^{2}$ Conforme a cartografia peirceana das ciências, as três ciências normativas Estética, Ética e Lógica (ou Semiótica) - configuram uma divisão da Filosofia, que, por sua vez, se fundamenta na Fenomenologia, uma ciência pré-normativa que meramente contempla os fenômenos. Sobre o assunto ver De Waal (2007).

${ }^{3}$ A relação entre abdução, indução e dedução, assim como todo o arcabouço teórico de Peirce, funda-se na articulação lógica de suas três categorias fenomenológicas: primeiridade (qualidade, mônada, instância do acaso), secundidade (relação/ reação, díada, instância da ação), terceiridade (representação/ mediação, tríada, instância do devir). As três categorias são dinâmicas, interdependentes e universais. Sobre o assunto ver Santaella (1992).

${ }^{4}$ No original: "pragmatism is the doctrine that every conception is a conception of conceivable practical effects". Esta e demais traduções das autoras.

Em perspectiva semelhante, Alsina (2005) afirma que a noção de verdade não está implícita no conceito de notícia, sendo a verdade uma questão de fé ou ideologia. "A veracidade da notícia é um tema absolutamente questionável" (p. 296). Ele ressalta que não há um conceito universal de notícia e menciona, entre outros, o conceito proposto por Abraham Moles: "A notícia é a narração de um acontecimento, de uma parte da vida individual ou coletiva, de algo verdadeiro ou fingido, provado ou não (boato)" (Moles, 1975, p. 495, citado por Alsina, 2005, p. 296). Assumindo uma perspectiva pragmática, Alsina situa a credibilidade da notícia no âmbito da Ética e exalta seus mecanismos de significação em detrimento do cânone da verdade. Tanto Lippman (2008) quanto Alsina (2005) resgatam, em suas considerações acerca da noção de verdade no jornalismo, a perspectiva peirceana do pragmatismo.

Charles Sanders Peirce (1839-1914) concebeu o pragmatismo, ou pragmaticismo ${ }^{1}$, como uma aplicação especial da Ética. Esta ciência normativa investiga a natureza das ações em conformidade com as crenças que as delineiam. No entanto, como a Ética pressupõe a distinção entre o que é e não é admirável, Peirce a baseou na Estética, ciência normativa que investiga a admirabilidade manifesta em qualidades de sentimento, sendo este o fundamento da ação. Crenças, portanto, se baseiam em sentimentos e se propagam por meio de hábitos de ação, os quais são examinados no âmbito da Lógica, ou Semiótica, ciência normativa que investiga a linguagem e seus processos de significação².

Abdução (inferência hipotética), indução (inferência sintética) e dedução (inferência analítica) correspondem aos tipos de raciocínio que conformam, segundo Peirce, a lógica da argumentação. Esta é preponderante em seu pragmatismo porque se relaciona à ação do pensamento, instância lógica da linguagem $^{3}$. Para Peirce (Peirce Edition Project, 1998), o pragmatismo é uma lógica de abdução porque, segundo ele, a lógica abdutiva é criativa e dela derivam as possibilidades de ação. Peirce expõe a máxima pragmática da seguinte maneira: "o pragmatismo é a doutrina de que toda concepção é uma concepção de efeitos práticos concebíveis" (Hartshorne \& Weiss, 1974, p. 196) e acrescenta que qualquer concepção "permite qualquer voo de imaginação, desde que essa imaginação acabe por se apossar de um possível efeito prático"5 (Hartshorne \& Weiss, 1974, p. 196). A máxima pragmática é normativa porque "nos conta como devemos definir nossos termos para que tenham significação" (De Wall, 2007, p. 137).

Com base em pressupostos teóricos do pragmatismo peirceano, Alsina (2005) toma a inferência abdutiva, responsável pela formação de hipóteses, como elemento criativo deflagrador dos mecanismos de significação da notícia. Ele considera que, diante de um acontecimento, o jornalista ${ }^{6}$ propõe uma 
hipótese explicativa baseada em certa proposta de interpretação e, a seguir, procura por dados que permitam verificá-la.

Segundo Peirce (citado por Hartshorne \& Weiss, 1974, p. 145), a abdução, ou hipótese explicativa, será considerada boa se puder ser verificada. Nesse caso, fortalecerá a crença que a delineia e se manifestará em hábito de ação, sendo este, em sua regularidade, o significado da crença. Mas, paradoxalmente, a regularidade do hábito de ação, que conforma a opinião relativamente duradoura, tende a refutar mecanismos de verificabilidade, pois "assim que uma crença firme é alcançada, ficamos inteiramente satisfeitos, quer a crença seja verdadeira, quer seja falsa"7 (Hartshorne \& Weiss, 1974, p. 375).

Conforme essa visão, a notícia pode ser entendida como processo de significação que se configura relativamente ao ato criativo que a deflagrou, cujo efeito prático será uma crença compartilhada na forma de opinião. O efeito prático de uma notícia, portanto, não é o reconhecimento social da verdade, mas a natureza da crença que deflagra, sendo esta sempre passível de revisão conforme o aprofundamento dos processos de verificação decorrentes das dúvidas que eventualmente incidem na significação da notícia. "Seus problemas seriam muito simplificados se, em vez de dizer que você quer conhecer a 'verdade', você simplesmente dissesse que quer alcançar um estado de crença inatacável pela dúvida"8 (Hartshorne \& Weiss, 1974, p. 416).

O reconhecimento de uma notícia como falsa, mediante o surgimento de dúvidas que impulsionam sua verificação, pode concorrer para o aprimoramento dos processos de significação que as notícias engendram de modo mais amplo, sejam elas produto da prática jornalística profissional ou não. Consequentemente, o esforço coletivo de verificação de notícias, motivado pela disputa em torno de crenças concorrentes, incrementa o aprimoramento do processo de significação das notícias. A noção de verdade, nessa visada pragmática, é um ideal jamais plenamente alcançável atuando normativamente no aprimoramento das crenças quando estas são submetidas ao escrutínio da dúvida. Trata-se, portanto, de processo de significação baseado em sistema de crenças apto a ser aprimorado, rumo a um ideal de verdade, se abalado pela incidência de dúvidas.

$\mathrm{Na}$ abordagem peirceana, a concepção pragmática da verdade relaciona-se à concepção pragmática de semiose, processo lógico de aprimoramento contínuo da significação. Nessa abordagem, signo é uma entidade triádica que se estabelece em referência ao objeto que o determina com vistas a produzir um efeito, seu interpretante, que terá a natureza de outro signo. O interpretante representa o objeto pela mediação do signo (representâmen), em associação com signos adjacentes por experiência colateral, ou seja, por familiaridade prévia com o objeto denotado pelo signo.
${ }^{5}$ No original: "It allows any flight of imagination, provided this imagination ultimately alights upon a possible practical effect".

${ }^{6}$ Note-se que Alsina (2005) aborda a prática profissional especializada da notícia.

${ }^{7}$ No original: "For as soon as a firm belief is reached we are entirely satisfied, whether the belief be false or true".

${ }^{8}$ No original: "Your problems would be greatly simplified, if, instead of saying that you want to know the 'Truth', you were simply to say that you want to attain a state of belief unassailable by doubt". 
${ }^{9}$ Objeto dinâmico é aquele que determina o signo, mas se localiza fora dele, em digressão infinita, sendo

o objeto imediato o modo pelo qual o objeto dinâmico se manifesta no signo. A potencialidade interpretativa do signo se encontra no próprio signo como interpretante imediato, mas o efeito concretamente gerado é o interpretante dinâmico, enquanto o interpretante final se refere ao ideal normativo de plenitude sígnica que norteia o desenvolvimento da semiose. Sobre o assunto, ver Alzamora (2017).

${ }^{10} \mathrm{~A}$ Teoria do Espelho surgiu no final do século XIX em contraposição ao jornalismo ideológico e partidário de então. Fundava-se na convicção de que as notícias seriam o espelho da realidade. Sobre o assunto, ver Traquina (2005).

${ }^{11}$ Os princípios fundadores da moral jornalística, que direcionam as regras de conduta profissional, têm caráter normativo e prescritivo.

Os valores principais são a busca pela verdade, a imparcialidade, a equidade e a honestidade. Sobre o assunto, ver Camponez (2009).
A noção de experiência colateral é de especial importância na compreensão do engajamento social que impulsiona a dinâmica transmídia de conteúdos noticiosos falsos ou distorcidos, pois descreve o modo pelo qual as associações sígnicas incidem no desdobramento da semiose. De acordo com Bergman (2010), essa noção torna-se preponderante na fase madura da teoria peirceana, quando os conceitos de semiose e pragmatismo se aproximam, porque à medida que os hábitos de ação se aprimoram, mais sofisticada se torna a experiência colateral e, consequentemente, mais acurada será a semiose.

Realidade (objeto dinâmico) e verdade (interpretante final) são ideais que norteiam o desenvolvimento pragmático da semiose, processo sígnico que se encontra permanentemente em estágio de incompletude 9 . Caso fosse possível alcançar plenamente as bordas da semiose, realidade e verdade se equivaleriam. Essa é a promessa, jamais cumprida, da Teoria do Espelho ${ }^{10}$, segundo a qual as notícias corresponderiam verdadeiramente à realidade que retratam. Trata-se de concepção que camufla o processo de significação decorrente da produção e circulação da notícia. Porém, tal imprecisão não deve ser entendida como desprezo pelos valores deontológicos do jornalismo" ${ }^{11}$, pois "reconhecer o valor não absoluto da verdade não significa ter de abandonar a responsabilidade por sua busca” (Santaella, 1992, p. 156).

Assim, paradoxalmente, a semiose das notícias falsas favorece o aprimoramento pragmático da notícia, de modo mais amplo, em sua busca normativa pela verdade. Quanto mais aderência o conteúdo noticioso falso ou distorcido engendra na forma de engajamento em redes sociais on-line, mensurável em ações como reações por emoji, comentários e compartilhamentos, mais capacidade tem de agenciar crenças concorrentes, o que impulsiona sua verificação mediante a inserção da dúvida em sua dinâmica semiótica.

De modo geral, processos de verificação da notícia buscam por evidências (índices) que comprovem ou refutem a notícia supostamente falsa. Índices estabelecem com seus objetos relação existencial ou referencial (Hartshorne \& Weiss, 1974, p. 283), por isso são mais facilmente verificáveis, já que operam semioticamente como rastros de seus objetos. mas, como o fenômeno da desinformação é complexo (Wardle \& Derakhshan, 2017) e envolve variadas modalidades semióticas, nem sempre esses conteúdos podem ser verificáveis a partir de vestígios indiciais. Mesmo a constatação indicial da falsidade nem sempre é suficiente para revisar a crença que delineia uma notícia, pois a crença se sustenta em arraigados hábitos de ação. Estes têm natureza simbólica, isto é, se baseiam em convenções sociais relacionadas a crenças duradouras. O caráter representativo do símbolo consiste em ser uma regra que será interpretada como tal pela força de um hábito (Hartshorne \& Weiss, 1974, p. 292). Assim, 
os conteúdos noticiosos falsos ou distorcidos, mesmo quando refutados após verificação, tendem a continuar gerando engajamento por meio de associação habitual com notícias baseadas em crenças semelhantes. O processo é exacerbado em dinâmica transmídia, na qual posicionamentos afins associam-se em conexões on-line/off-line para expandir continuamente a teia noticiosa em prol de uma crença comum, a despeito de evidências em contrário. A natureza pragmática de tal dinâmica, porém, tende a atuar no aprimoramento progressivo dos mecanismos de significação da notícia.

\section{COSMOLOGIA PEIRCEANA E TRANSMÍDIA}

Nos últimos anos de sua vida, quando aprofundava seus estudos acerca do pragmatismo, Peirce dedicou-se a desenvolver uma cosmologia evolutiva, relativa ao modo pelo qual os organismos e seus ambientes alteram-se mutuamente, em níveis crescentes de interação. O pragmatismo de Peirce pode ser entendido como uma versão da lógica evolutiva de Darwin, que havia publicado The origin of species em 1859 (Fisch, citado por Ketner \& Kloesel, 1986) ${ }^{12}$. De acordo com Colapietro (2004), sob influência do evolucionismo de Darwin, o pragmatismo de Peirce passou a enfatizar, a partir de 1903, o aprimoramento lógico do significado, o que pressupõe o aprimoramento progressivo das crenças e dos hábitos de ação que estas envolvem.

A cosmologia evolutiva de Peirce funda-se na ideia de que os hábitos podem alterar-se gradualmente, favorecendo uns aos outros de modo cada vez mais coerente e sofisticado. Isso ocorre porque os hábitos são os significados das crenças e estas são propensas ao aprimoramento contínuo mediante o surgimento da dúvida. "Se uma nova crença produz ações eficazes, o ser humano sobrevive feliz no ambiente. Se uma nova crença produz uma ação ineficaz, ele é hostilizado no ambiente" (Shook, 2002, p. 83). É o que se observa quando notícias que circulam amplamente em conexões digitais são verificadas e comprovadas como falsas, tornando-se alvo de hostilidades. Nesse caso, posicionamentos afins atuam de modo sincronizado com o intuito de revelar a inconsistência do relato noticioso em questão pela inserção da dúvida e posterior verificação. As agências de fact checking ${ }^{13}$, especializadas em verificar conteúdos noticiosos que circulam amplamente na internet, são muito relevantes nesse processo. Por outro lado, posicionamentos opostos investem no compartilhamento intenso da referida notícia, independente de esta ter sido verificada como falsa, impulsionados por uma crença comum.

As crenças concorrentes, mediadas pela circulação de conteúdos noticiosos falsos ou distorcidos, buscam alcançar propagabilidade dominante em ações
${ }^{12}$ Essa concepção evolutiva marcou profundamente tanto o pragmaticismo de Peirce quanto as demais vertentes pragmáticas que emergiram das discussões no Clube Metafísico, em Cambridge, nos primeiros anos da década de 1870. Posteriormente, na segunda metade do século $\mathrm{XX}$, proliferaram estudos em torno do que se convencionou chamar de Ecossemiótica, estudo das relações semióticas entre os organismos e seus ambientes. Sobre o assunto, ver Nöth (1996) e De Waal (2007).

\footnotetext{
${ }^{13}$ De acordo com Uscinski e Butler (2013), as práticas metodológicas de checagem de notícias sobre política compartilham o pressuposto tácito de que os fatos são inequívocos. Em perspectiva semelhante, defendemos que os procedimentos de checagem são adequados para a verificação sígnica indicial, mas limitados para outras construções sígnicas.
} 
que integram a mente algorítmica e a mente humana nas conexões digitais. Em ambiente digital, algoritmos interferem nos processos interacionais, por exemplo, por meio de sistemas de recomendação, assim como robôs atuam na propagação de determinadas hashtags, as quais, por sua vez, impulsionam a circulação de notícias a elas relacionadas. Enquanto a mente algorítmica atua predominantemente em relações indiciais de repetição, como é o caso dos Trending Topics do Twitter, a mente humana baseia-se em crenças que se manifestam em hábitos de ação notadamente simbólicos, porque são fundados em convenções sociais culturalmente estabelecidas (Alzamora \& Andrade, 2016).

A ação de compartilhar notícias que reverberam uma crença comum é típica dos hábitos de ação baseados em convenções sociais culturalmente estabelecidas, embora o esforço repetitivo responsável por integrar ações algorítmicas e humanas no ecossistema midiático tenha natureza indicial. Já o impulso criativo que deflagra a expansão desse ecossistema tem natureza icônica, porque se baseia em relações qualitativas de semelhança e analogia. Ícones remetem a seus objetos por força de uma qualidade e, por isso, podem referir-se a qualquer coisa com a qual se assemelhem (Hartshorne \& Weiss, 1974, p. 276). Conjuntamente, essas ações delineiam uma espécie de cosmologia evolutiva do ecossistema midiático e das interações que este propicia em conexões digitais. Trata-se de processo marcadamente transmidiático, conforme se demonstrará a seguir.

Peirce chamou de agapismo a capacidade de sincronização e cooperação mútua entre mentes e meio ambiente; de sinequismo o fluxo contínuo de um objeto a outro; e de tiquismo os desvios espontâneos e contingentes, em semelhança à ideia de mutação. "O princípio cosmológico peirceano do sinequismo alega que tudo o que existe pode ter alguma espécie de continuidade com outra coisa, e que tudo o que existe no universo está de alguma forma em união indireta com as demais" (Shook, 2002, p. 81). Em certa medida, essa perspectiva remete à ideia de transmídia, segundo a qual os textos midiáticos contemporâneos se propagam na interseção dos meios, embora cada configuração textual apresente autonomia semiótica e seja continuamente expansível pela ação integrada de produtores, consumidores e algoritmos. A dinâmica transmídia pressupõe propagação de informações por meio da cooperação mútua entre mentes humana e algorítmica nos ambientes midiáticos (agapismo), configurando fluxo contínuo de informações em conexões digitais (sinequismo) com base em extensões criativas (tiquismo). A circulação de conteúdos noticiosos falsos ou distorcidos é transmidiática porque opera na interseção dos meios, configurando teia textual que se expande em ações de compartilhamento que envolvem o entrelaçamento de mentes humana e algorítmicas em torno de uma crença comum. 
O termo transmídia, popularizado por Henry Jenkins a partir da publicação de seu livro Convergence culture (2006), foi cunhado em 1991 por Marsha Kinder (1991) para descrever a intertextualidade transmidiática em produtos midiáticos afins, como filmes, brinquedos, narrativas de fãs etc. Conforme Jenkins $(2008)^{14}$, transmídia funda-se na participação, sendo esta moldada por protocolos sociais e culturais. A circulação transmídia de conteúdos noticiosos falsos ou distorcidos funda-se em participação, cujos protocolos sociais e culturais atrelam-se à interação cosmológica entre ambientes midiáticos por meio de ações integradas de mentes humanas e algorítmicas em conexões digitais. A propagação de conteúdos noticiosos falsos ou distorcidos ocorre em consonância com a cultura de convergência, na qual "consumidores são incentivados a procurar novas informações e fazer conexões em meio a conteúdos dispersos" (Jenkins, 2008 , p. 28), assim como se inscrevem na cultura das conexões, relacionada a

um modelo híbrido e emergente de circulação em que um mix de forças de cima pra baixo e de baixo pra cima determina como um material é compartilhado, através de cultura e entre elas, de maneira muito mais participativa (e desorganizada). (Jenkins, Green, \& Ford, 2014, p. 11)

Mais recentemente, Jenkins (2017) adotou a denominação lógica transmídia para designar a interação pretendida entre consumidores, produtores e textos nas conexões digitais. A lógica transmídia funda-se nos princípios da narrativa transmídia (Jenkins, 2009; 2010): potencial de compartilhamento/profundidade; continuidade/multiplicidade; imersão/extração; construção de universos; serialidade; subjetividade; e performance. Esses princípios podem ser entendidos como modos semióticos de atuar transmidiaticamente no ambiente digital. Por exemplo, a ideia de continuidade sígnica, ou sinequismo, aplica-se à dinâmica transmídia com base na ideia de mediação, ação continuamente transformadora do signo, ou semiose. Adotamos, assim, a definição peirceana de lógica (ou semiótica) para descrever a lógica transmídia como uma dinâmica (semiose) que incorpora desvios resultantes de associações (experiência colateral) à referência (objeto) para expandir continuamente os significados (interpretante).

De acordo com Jenkins (2010), a indústria midiática frequentemente fala sobre continuidade em termos da informação aceita como parte da versão definitiva de uma história particular. Em contraste, multiplicidade refere-se às variadas versões alternativas à história canônica. Conforme a perspectiva pragmática da semiose, multiplicidade não se opõe à continuidade, pois pode ser entendida como a capacidade associativa (experiência colateral) da representação sígnica, a qual garante o componente criativo necessário para que a mediação sígnica
${ }^{14}$ Utilizamos a tradução brasileira de Convergence culture (2006), publicada em 2008. 
opere por continuidade lógica. Desse modo, a circulação de uma notícia em conexões de redes sociais on-line opera por continuidade sígnica, que tanto pode endossar o conteúdo noticioso quanto contestá-lo por familiaridade prévia (experiência colateral) com aquilo que o conteúdo noticioso denota. Nessa perspectiva, multiplicidade de significados (interpretantes) concorre para a expansão transmidiática (semiose) do relato noticioso.

Outros autores também reconhecem o potencial da semiótica para a compreensão da lógica transmídia. Bertetti (2014), por exemplo, argumenta que a semiótica textual oferece recursos relevantes para o entendimento da lógica transmídia e, bem antes, Scolari (2009) já afirmava que a semiótica estuda objetos (textos) para compreender processos, o que a torna útil para descrever os instrumentos que criam significado na narrativa transmídia. Em um estudo sobre transmediação baseado na semiótica peirceana, Elleström (2014) evoca as relações icônicas, indiciais e simbólicas para explicar os processos de representação relacionados aos mecanismos de transmissão de características midiáticas de um meio a outro.

Sob o ponto de vista pragmático da semiose peirceana, a dinâmica transmídia é um processo sígnico em contínua expansão reticular, envolvendo a proliferação variada de interpretantes. Por esse prisma, a incompletude produtiva do interpretante é tomada como parâmetro conceitual para entender a maneira pela qual os hábitos de consumo midiático conferem especificidades à dinâmica transmídia por meio de associações sígnicas baseadas em experiências colaterais (Alzamora \& Gambarato, 2014). A potencialidade interpretativa do signo (interpretante imediato) pode ser entendida na semiose transmidiática como uma espécie de convite à participação, o qual só se torna um novo signo (interpretante dinâmico) pela ação sígnica associativa (experiência colateral) (Alzamora, 2018).

Assim, quanto mais significados um conteúdo noticioso falso ou distorcido evoca nas interações que agencia, mais conexões tende a alcançar de um ambiente midiático a outro. Em dinâmica transmídia, conteúdos noticiosos falsos ou distorcidos se propagam continuamente de um ambiente midiático a outro, por meio da multiplicidade de ações que agenciam em conexões digitais. Nesse contexto, a disputa em torno de crenças concorrentes mediadas por conteúdos noticiosos falsos ou distorcidos assume contornos de ativismo transmídia.

\section{ATIVISMO TRANSMÍDIA EM TORNO DE \#FAKENEWS}

A dinâmica transmídia abarca diferentes vertentes, como transmedia storytellig, transmedia branding, transmedia performance, transmedia learning, entre 
outras variações (Jenkins, 2010). No campo das mobilizações sociopolíticas, Jenkins (2016) faz referência à noção de ativismo transmídia (transmedia activism), termo cunhado por Lina Srivastava (2009) para designar os processos coletivos e criativos que coordenam uma narrativa cultural em expansão midiática, definindo as mudanças sociais como fruto de soluções sistêmicas. $\mathrm{O}$ termo diz respeito à produção reticular de conteúdos com o objetivo de gerar consciência, engajamento e ação para a estruturação de mudanças. Trata-se de uma dinâmica transmídia, porque essa forma de ativismo baseia-se na multiplicação de atores em rede, aptos a criar pontos variados de entrada na narrativa socialmente construída para questões e soluções ligadas ao tema, utilizando múltiplas plataformas e linguagens.

Soriano (2016) destaca que esse tipo de dinâmica transmídia envolve estratégias de intertextualidade radical e multimodalidade para abordar públicos heterogêneos em rede. A primeira estratégia diz respeito ao movimento da narrativa coletiva por meio de fragmentos textuais espalhados por diversas plataformas. Já a segunda corresponde às possibilidades lógicas oferecidas por esses textos, cuja tessitura transmidiática favorece o engajamento social. A sinergia entre as várias partes do sistema de mídia contribui para o desdobramento de subtemas, maximizando pontos de contato com variados nichos de público.

Vieira (2013) discorre sobre a necessidade de classificar a pré-disposição social para diferentes efeitos práticos com o intuito de gerar engajamento. Ele sintetiza três formas básicas em evolução integrada: aderência, mobilização e ativismo. A primeira seria o grau mais baixo de comprometimento, prevalecendo uma mera identificação temática com o evento. Conforme o pragmatismo peirceano, é nesse estágio que a semiose pode ser redirecionada pela inserção da dúvida no processo sígnico. Já a mobilização seria uma forma intermediária, quando se deflagram ações de propagação em rede. Trata-se, conforme o pragmatismo peirceano, de domínio semiótico, no qual as ações se propagam ancoradas em crenças compartilhadas. O terceiro nível seria a concretização das estratégias anteriores voltadas para o envolvimento máximo, concentrando forças e agindo sistematicamente em prol da visibilidade da causa. No pragmatismo peirceano, esse estágio é modelado por arraigados hábitos de ação, cuja repetição continuada reflete o enrijecimento das crenças que os sustentam e as qualidades de sentimento que os impulsionam para a ação. Esses processos estão interligados e se retroalimentam, conformando uma rede de significações cada vez mais densa e multifacetada.

Por esse viés, a circulação de conteúdos noticiosos falsos ou distorcidos deriva de relações entre os tipos de engajamento que essas notícias acionam com base nas crenças manifestas em determinados posicionamentos políticos. 
${ }^{15}$ No original: "Omnipresent sharing features stimulate users to spread and repeat breaking news".

${ }^{16}$ Recurso que mostra a relevância de determinados assuntos por meio do volume gerado pelas conversações na rede, em um curto período de tempo (Groshek \& Groshek, 2013).
Esse processo favorece o desenvolvimento de pontos de contato entre ações afins, estimulando a passagem do engajamento por aderência ao engajamento ativista, pela mediação do engajamento por mobilização.

Nas conexões de redes sociais on-line, a propagação de conteúdos noticiosos falsos ou distorcidos é condicionada pela arquitetura das plataformas, instância mediadora que define modos de interação por meio das ações que tecnicamente propicia, como compartilhar, comentar e reagir por emoji. Assim, a circulação de conteúdos noticiosos falsos ou distorcidos é também mediada por instância sociotécnica, porque "recursos de compartilhamento onipresentes estimulam os usuários a espalhar e repetir as últimas notícias"15 (Poell \& van Dijck, 2015, p. 530). Isso propicia a propagação de ações voltadas para o ativismo transmídia, instituindo hábitos de ação provisórios, os quais concorrem para consolidar uma crença comum por compartilhamento em larga escala. É exemplo o caso de certas notícias que vigoram nos trends ${ }^{16}$ das plataformas on-line por meio de ações de ativismo transmídia que integram as mentes humanas e algorítmicas nesses ambientes midiáticos.

De acordo com Igarza (2010), os rearranjos das audiências nos ambientes digitais são consolidados pelos processos de adesão e recomendação de conteúdo, estabelecidos dentro de cada círculo de amizade. A anuência cresce pela sensação de credibilidade, em conformidade com a instantaneidade e o dinamismo do sistema. Este processo estimula a proximidade por interesses afins, abrindo espaço para o intercâmbio de valores, geração de confiança e produção de conhecimento. Trata-se de uma "dinâmica de boato", conforme Sarlo (2011).

A conversação entre os pares marca a disseminação e o fortalecimento de posicionamentos políticos em conexões multiplataformas. Segundo Dahlgren (2013), o engajamento está condicionado aos aspectos racionais e afetivos da dinâmica mental, incorporando modos de expressão cultural que são mediados pela mídia. Como as redes sociais on-line são espaços de relacionamento por excelência (Sarlo, 2011), tornam-se espaço privilegiado para o compartilhamento de crenças por engajamento social. Ao mesmo tempo, são ambientes midiáticos que contribuem para o surgimento da dúvida, já que propiciam a contiguidade entre crenças concorrentes, favorecendo, desse modo, processos de verificação das notícias pelo escrutínio da dúvida.

É exemplo desse processo a hashtag \#fakenews, cujo propósito é denunciar supostas notícias falsas. Essa hashtag vem sendo utilizada no Twitter, Facebook e Instagram, com esse propósito em vários idiomas, inclusive em postagens brasileiras. Para compreender seu potencial de propagação, coletamos automaticamente essa hashtag no Twitter, durante os dias 27 e 28 de janeiro de 2018, com o intuito de mensurar a repercussão nesse ambiente midiático do 
julgamento em segunda instância do ex-presidente Luís Inácio Lula da Silva, realizado em 24 de janeiro de 2018. Em 24 horas, coletamos 109.272 tweets com auxílio da ferramenta Tags ${ }^{17}$, que compreende a Interface de Programação de Aplicativos (API - do inglês Application Programming Interface) de pesquisa, focada na relevância de tweets publicados e compartilhados. Das publicações brasileiras coletadas sob essa hashtag, a maioria tinha como foco notícias sobre o ex-presidente Lula. No Instagram, mapeamos 476.622 postagens relacionadas a essa hashtag por meio da ferramenta de contagem da própria plataforma, compreendendo a disseminação de memes e alegorias políticas. Já no Facebook, por meio de coleta manual entre os dias 27 e 28 de janeiro, monitoramos 100 postagens de páginas e perfis públicos que mencionavam essa hashtag.

Os dados coletados revelaram que o uso dessa hashtag contempla majoritariamente contestações sem provas, apontando de forma passional para inverdades baseadas em sistemas de crenças concorrentes. Nem sempre a hashtag era associada às notícias de cunho jornalístico, pois a expressão fake news, no contexto das redes sociais on-line, assume um sentido mais amplo de notícia, referenciando qualquer conteúdo publicado, independentemente da fonte. Seu efeito prático, portanto, não é o reconhecimento social da verdade, mas a tentativa de consolidação de crenças comuns mediadas por esse dispositivo simbólico. A hashtag surge, então, como símbolo de posicionamento político firmado em hábitos de ação derivados de crenças pré-estabelecidas. Conforme a abordagem peirceana, símbolo é "um signo que se refere ao objeto que ele denota em virtude de uma lei, usualmente uma associação de ideias gerais, que opera de modo a ser interpretado como se referindo àquele objeto" (Hartshorne \& Weiss, 1974, p. 283). A perspectiva de ativismo transmídia que emerge do uso social dessa hashtag atua prioritariamente no sentido de promover a fixação da crença compartilhada por associação simbólica de ideias afins. O processo de fixação de crenças, porém, varia conforme os métodos empregados.

\section{FIXAÇÃO DAS CRENÇAS E ENGAJAMENTO SOCIAL}

Em um dos primeiros textos que publicou sobre o pragmatismo, A fixação das crenças (1877), Peirce propôs quatro métodos para fixar a crença - referindo-se "à maneira de chegar às ideias que se instalam na mente das pessoas como hábitos, costumes, tradição"18 (Hartshorne \& Weiss, 1974, p. 375): tenacidade, autoridade, a priori e científico. Para Peirce, a crença se manifesta no estabelecimento de certo hábito de ação (Hartshorne \& Weiss, 1974, p. 53) cuja regularidade delineia um posicionamento comum na forma de opinião compartilhada. Os quatro métodos permitem compreender como o processo

${ }^{17}$ Recuperado de https://tags. hawksey.info/

${ }^{18}$ No original: "The term 'fixation of belief' refers to the way of arriving at ideas that settle own in the mind of people as habits, customs, tradition".

MATRIZes 
${ }^{19}$ Em entrevista à $\mathrm{BBC}$, publicada em 17 de fevereiro de 2017, o fundador do Facebook, Mark Zuckerberg, disse que as notícias falsas, a polarização de opiniões e as "bolhas ideológicas" estariam prejudicando o entendimento entre as pessoas e ameaçando o projeto original do Facebook, voltado para interações pessoais (Ahmed, 2017).

${ }^{20}$ A partir da segunda metade do século XX, a imprensa passou a ser compreendida como uma espécie de quarto poder, ou contrapoder, relativamente aos poderes legislativo, executivo e judiciário. O quarto poder se caracteriza por vigiar os outros três poderes em nome dos interesses civis que a imprensa representa. Mas a gradativa aproximação dos grupos midiáticos com os interesses políticos e econômicos dos poderes que deveriam vigiar, culminaram na chamada crise da imprensa, ou crise do quarto poder. Ramonet (2013) sugere que os observatórios de mídia e as ações ativistas em redes sociais on-line configuram uma espécie de quinto poder, sendo este caracterizado pela vigilância cidadã da imprensa, do legislativo, do executivo e do judiciário. de formação da opinião articula manifestações diferenciadas da crença, impactando, conforme se argumenta aqui, em processos específicos de engajamento social com a notícia pretensamente falsa.

No método da tenacidade, a opinião é estabelecida simplesmente por alguém se aferrar obstinadamente às próprias crenças. "Atemo-nos tenazmente, não somente a crer, mas a crer exatamente naquilo que cremos" (Peirce, citado por De Waal, 2007, p. 31). O engajamento social baseado no método da tenacidade tende a ignorar evidências em contrário e a desconsiderar opiniões divergentes, caracterizando a forma mais comum de engajamento social em torno de conteúdos noticiosos falsos ou distorcidos. Esse método resulta na formação de bolhas ideológicas ${ }^{19}$ em contexto de polarização política.

Uma pessoa poderia escolher evitar ativamente a interação com pessoas de opinião diferentes, ou poderia desenvolver o hábito de desprezar e rejeitar imediatamente tudo o que desafiasse suas próprias crenças. Teóricos de conspiração com frequência pensam dessa maneira. Adotam completamente todas as evidências a favor de suas visões ...e e rejeitam ou 'reinterpretam' tudo o que se acumule contra elas. (De Waal, 2007, p. 33)

No método da autoridade, a fixação da crença é coagida por uma instituição. As evidências contrárias são aqui propositadamente isoladas por uma instituição reguladora, como imprensa e governo, por exemplo. O reconhecimento dos mecanismos de atuação desse método é propulsor, por exemplo, de denúncias cidadãs contra conteúdos noticiosos falsos ou distorcidos que são institucionalmente produzidos com o intuito de manipular opiniões. Manifesta-se também em postagens cidadãs em redes sociais on-line, as quais buscam dar visibilidade a notícias propositadamente ignoradas pelos veículos tradicionais de imprensa. O engajamento social balizado pelo método da autoridade se manifesta em interações transmidiáticas que enfatizam a chamada crise da imprensa associada ao quarto poder $^{20}$, caracterizando um exemplo típico de ativismo transmídia.

No método a priori, a crença é fixada ao se procurar aquelas crenças concordantes com a razão. De acordo com De Waal (2007), esse método não apenas nos dá um impulso a acreditar, como os outros dois, mas também define o que deve ser crível conforme o logicamente plausível. Já o método científico difere-se dos três anteriores, porque neste as ideias são fixadas não por aquilo que desejamos acreditar, mas "por algo sobre o que nosso pensamento não tem efeito algum" (Peirce, citado por De Waal, 2007, p. 35), como é o caso das leis da física, por exemplo.

As associações de ideias (experiência colateral) incidem diferentemente na semiose conforme os métodos de fixação de crenças empregados. Práticas interacionais típicas de ativismo transmídia fundam-se prioritariamente nos 
métodos da tenacidade e da autoridade para fixar crenças relacionadas à disseminação de conteúdos noticiosos falsos ou verdadeiros. Em ambos, o engajamento social, manifesto em ações integradas de reagir por emoji, comentar e compartilhar uma notícia, tem o propósito de gerar interação ampliada em torno de uma crença comum. Os outros dois métodos também são acionados para referendar ou contestar notícias supostamente falsas, porém em menor escala, porque acionam mecanismos mais específicos de familiaridade prévia (experiência colateral) com o objeto que o signo denota.

\section{PRÁTICAS INTERACIONAIS EM TORNO DO JULGAMENTO DO EX- PRESIDENTE LULA}

Em 12 de julho de 2017, o ex-presidente Luís Inácio Lula da Silva foi condenado, em primeira instância, a nove anos e seis meses de prisão, por lavagem de dinheiro e corrupção passiva, acusado de receber propina da construtora OAS em troca de favorecimento da empreiteira em contratos com a Petrobras. A prova apresentada foi a suposta aquisição e reforma de um apartamento triplex, na cidade do Guarujá, em São Paulo, no valor de R \$3,7 milhões. Com a condenação, a defesa protocolou o pedido de revisão em segunda instância da Justiça, recorrendo ao Tribunal Regional Federal da $4^{\mathrm{a}}$ Região (TRF4), em Porto Alegre, para reverter a decisão do juiz Sérgio Moro. A audiência aconteceu no dia 24 de janeiro de 2018 e manteve a condenação, aumentando a pena para doze anos de prisão.

No período final do julgamento, houve aumento considerável de circulação de conteúdos noticiosos falsos ou distorcidos sobre o assunto em redes sociais on-line. De acordo com dados apresentados pelo "Monitor do Debate Político no Meio Digital" (Facebook, 2018) - projeto conduzido pelo GPOPAI/USP para mapear, mensurar e analisar o ecossistema de debate político on-line - das dez notícias sobre política mais compartilhadas no Facebook no Brasil, nove referiam-se ao depoimento do ex-presidente no TRF4. Além da imprensa tradicional, também circularam vários links da imprensa alternativa, marcada por forte viés ideológico, demarcando ainda mais a polarização política em torno de crenças concorrentes. Para conferir a veracidade das informações compartilhadas, a Agência Lupa, especializada em fact-checking, avaliou as principais notícias disseminadas sobre o assunto nas redes sociais on-line (Lupa, 2018).

De acordo com a Lupa, uma das primeiras notícias supostamente falsas sobre o tema foi publicada pelo site da Revista Fórum (Forum, 2018), que afirmava ser aquela a maior manifestação da história de Porto Alegre em prol de Lula. A notícia foi disseminada no Facebook um dia antes do julgamento e alcançou onze mil interações (reações por emoji, compartilhamentos e comentários), conforme dados do 


\section{$\mathbf{P}$}

${ }^{21}$ Recuperado de https:// buzzsumo.com/

BuzzSumo $^{21}$, ferramenta de monitoramento de redes sociais on-line. Mas, conforme dados publicados pela Agência Lupa, o maior protesto de rua em Porto Alegre ocorreu no dia 13 de março de 2016, a favor do impeachment da então presidente Dilma Rousseff, o qual atraiu cem mil pessoas, segundo dados da Brigada Militar, e cerca de 140 mil, pelos dados dos organizadores do evento. Para corroborar o diagnóstico de apoio a Lula, um perfil privado publicou no Facebook uma foto aérea com o intuito de mostrar a grandiosidade da mobilização, alcançando 33 mil compartilhamentos. Todavia, segundo a checagem realizada pela Agência Lupa, a imagem era reprodução de um protesto que aconteceu na Venezuela, em 2010.

Nesse contexto, crenças dissonantes se mobilizaram em esforço coletivo para levantar dúvidas acerca de notícias que referendavam posicionamentos políticos contrários. É o caso da notícia propagada pelo site Papo TV (Rodrigues, 2018) questionando recurso apresentado em favor do ex-presidente ao TRF4. No documento original, havia um pedido de prescrição dos crimes apontados pela sentença imposta pelo então juiz Sérgio Moro em primeira instância. No entanto, conforme notícia publicada pelo site Papo $T V$, a defesa teria admitido a culpa de Lula no caso do tríplex, o que foi verificado como falso pela Agência Lupa.

Os exemplos mencionados sublinham a busca por vestígios indiciais no processo de checagem. Entretanto, nem sempre isso é suficiente para revisar crenças relacionadas ao compartilhamento de conteúdos noticiosos falsos ou distorcidos, porque tais crenças se fundamentam em arraigados hábitos de ação que resistem às evidências em contrário. É o caso do suposto texto escrito pela atriz Marieta Severo descrevendo sua decepção em relação ao ex-presidente Lula, o qual alcançou ampla circulação no âmbito da dinâmica transmídia de notícias relacionadas ao julgamento em segunda instância do ex-presidente. A atriz é conhecida por apoiar os movimentos de esquerda e ser eleitora de Lula. No dia do julgamento, a deputada federal Jandira Feghali (Partido Comunista do Brasil do Rio de Janeiro PCdoB/RJ), considerada líder da oposição ao governo de Michel Temer na Câmara dos Deputados, publicou, em sua página do Facebook, uma foto de Marieta Severo em apoio a Lula. Assinada pela Central Única dos Trabalhadores (CUT), essa publicação, compartilhada por Marieta Severo, reivindicava a participação do ex-presidente nas eleições de 2018, sob a hashtag \#EleiçãoSemLulaÉFraude.

A postagem alcançou 551 compartilhamentos e, das 4,4 mil reações na forma de emoji, 3,9 mil foram reações positivas em forma de polegares, $420 \mathrm{em}$ forma de coração, 41 foram reações negativas em forma de sarcasmo, dezessete em forma de raiva, oito em forma de surpresa e dois em forma de tristeza. Postula-se, então, que a postagem resultou em reações por emoji majoritariamente positivas. $\mathrm{O}$ campo dos comentários abarcou reações positivas e negativas que fomentaram o embate de argumentos em torno de crenças concorrentes. 
No dia seguinte, o texto intitulado "Os erros de Luís"22, atribuído a Marieta Severo, começou a ser compartilhado em redes sociais on-line. O texto citava uma série de erros cometidos pelo ex-presidente, que culminaram no decreto de sua prisão. O conteúdo foi recebido com desconfiança por leitores favoráveis ao ex-presidente, mas foi largamente compartilhado por aqueles que se mobilizavam nas redes sociais on-line motivados por crença contrária. A disseminação de textos de opinião atribuídos às celebridades é estratégia recorrente para propagar notícias falsas em ambiente digital, porque seu fundamento icônico potencializa ações de compartilhamento em dinâmica transmídia. Trata-se de fundamento icônico porque esse tipo de construção sígnica opera qualitativamente por sedução e, desse modo, impulsiona sentimentos de adesão ao texto, resultando em ações de compartilhamento.

No dia 26 de janeiro, o site Boatos.Org realizou a checagem da notícia e constatou que era falsa (Matsuki, 2018). Um dos procedimentos de checagem foi uma busca inversa para rastrear indícios do comportamento de Marieta Severo que pudessem confirmar o conteúdo compartilhado. Todavia, a última ação on-line realizada pela atriz foi sua assinatura em uma petição para Lula poder ser candidato à presidência em 2018, estando alinhada à publicação realizada anteriormente pela deputada Jandira Feghali. A hashtag \#fakenews foi usada no Twitter como forma de contestação do conteúdo noticioso, o que confere tentativa de revisão simbólica da crença provisoriamente estabelecida em torno do referido texto.

No Facebook, por meio de coleta manual pelo título "Os erros de Luís", identificamos que o perfil privado com maior número de interações em torno dessa notícia alcançou 108 mil curtidas, 83.668 compartilhamentos e apenas treze comentários. Das reações, 89 mil foram reações em forma de polegares, doze mil em forma de coração, 5,5 mil em forma de surpresa, $655 \mathrm{em}$ forma de sarcasmo, 169 em forma de raiva e $116 \mathrm{em}$ forma de tristeza. Mesmo depois de refutada a veracidade da informação pelo site Boatos. Org, essa postagem no Facebook continuou recebendo comentários referendando o teor do texto, ainda que a autoria fosse falsa. Observou-se que a referida postagem continuou sendo compartilhada até pelo menos o mês de maio, portanto, após a prisão de Lula, no dia 7 de abril. Isso demonstra como o método da tenacidade opera transmidiaticamente na fixação de crenças disseminadas por fake news, independente de evidências em contrário ${ }^{23}$.

$\mathrm{O}$ uso de hashtags nas redes sociais on-line, abarcando posicionamentos políticos distintos por associação a notícias afins, impulsiona a dinâmica transmídia desse tipo de conteúdo. No dia 24 de janeiro, duas hashtags contrárias movimentaram os trends das plataformas digitais. Os usuários favoráveis ao ex-presidente usavam a hashtag \#cadêaprova para argumentar que Lula havia sido condenado sem a apresentação de evidências. Já os usuários contrários

${ }^{22}$ Uma das razões que motivou a desconfiança sobre a veracidade do texto foi o erro na grafia do nome do expresidente, posto que ele assina Luiz $\operatorname{com} z$.

${ }^{23}$ Outros fatores também são fundamentais na propagação de crenças concorrentes, como a utilização de robôs para aumentar a visibilidade midiática do conteúdo. Porém, para o recorte deste trabalho não mensuramos a mediação não humana durante a análise. 
${ }^{24}$ Recuperado de https:// www.4kdownload.com/pt-br/ products/product-stogram utilizaram a hashtag \#molusconacadeia, uma variação de \#lulanacadeia, que vigora desde 2016 nas mobilizações on-line. Observou-se o uso concomitante das duas hashtags no Facebook, Twitter e Instagram, atreladas a postagens fundadas em crenças concorrentes, o que demonstra o potencial simbólico das referidas hashtags para aglutinar posicionamentos políticos afins.

A coleta realizada no Twitter por meio da ferramenta Tags resultou em 24.772 tweets com \#cadêaprova e 91.586 tweets com \#molusconacadeia. No Facebook, foram coletadas manualmente as primeiras cinco postagens referentes às duas hashtags, pois foram as publicações com maior interação no período (curtidas, comentários e compartilhamentos). No Instagram, por meio da ferramenta $4 \mathrm{~K} \mathrm{Stogram}^{24}$, foram coletadas 1.204 postagens com \#cadêaprova e $1.338 \mathrm{com}$ \#molusconacadeia. Em todas as plataformas investigadas, as duas hashtags apresentaram forte conexão com a expressão fake news, revelando a disputa pelo valor semiótico da verdade em torno dessa simbologia.

Observa-se, assim, que essas hashtags impulsionaram a dinâmica transmídia sobre o tema, enfatizando a disseminação de conteúdo noticioso, falso ou verdadeiro, com o propósito de consolidar certa crença no ambiente transmidiático por associação sígnica (experiência colateral). Todavia, quanto mais um conteúdo noticioso fundado em crença concorrente se expande transmidiaticamente, mais ele é submetido ao escrutínio da dúvida. A designação simbólica fake news, que enfatiza processos de verificação da notícia, foi, então, largamente compartilhada na forma de hashtag com o intuito de revisar crenças e, consequentemente, mudar opiniões acerca do tema noticiado.

Um exemplo disso são as estratégias criadas por grupos ativistas para dar visibilidade às suas crenças comuns. Para impulsionar seu ranqueamento, a página do Partido dos Trabalhadores (PT), no Facebook, realizou uma publicação convocando seus ativistas para um tuitaço no dia do julgamento. As hashtags, originalmente utilizadas como recurso indicial de monitoramento digital, tornaram-se, nesse caso, símbolos de um posicionamento comum, criando conexões variadas em contextos sígnicos multiplataformas (Alzamora \& Andrade, 2016). Assim, o objetivo da ação coletiva no Facebook era reforçar um posicionamento político na interseção de postagens mediadas por uma mesma hashtag. Ao mesmo tempo, quando a hashtag passa a vigorar nos trends, aumenta sua influência na agenda pública. Segundo Groshek e Groshek (2013), isso pressupõe a emergência de uma Agenda Trending, o que expande o alcance transmidiático da referida ação.

Poell e van Dijck (2015) afirmam que os trends identificam as novidades mais recentes e escalonam os tópicos de tendência por região, cidade ou país. Porém, por mais que o ranqueamento seja fruto do engajamento social, os autores advertem que os trends podem não traduzir diretamente os interesses dos usuários, pois são 
mediados também pelos processos algorítmicos ${ }^{25}$. São eles que ordenam a relevância de determinada informação, podendo incluir ou excluir sinais particulares. Nem sempre os tópicos de tendência são determinados pelo volume de tweets, porque o algoritmo se adapta em razão da velocidade de mudança dos termos-chave.

Os autores também destacam semelhanças na relação dos algoritmos com o feed de notícias (FB) ${ }^{26}$ do Facebook e outras redes sociais on-line usadas por ativistas. De acordo com Poell e van Dijck (2015), essas plataformas permeiam a comunicação pessoal cotidiana, oferecendo oportunidade para o compartilhamento de causas sociais, culturais e políticas. Porém, os interesses que ligam os usuários dispersos nessas redes sociais on-line geram momentos instantâneos e breves de união. Essa ligação, inevitavelmente, se dissolve quando são conectados algoritmicamente ao próximo tópico de tendências. A apresentação contínua de novos tópicos é o que mantém as plataformas ativas, estimulando o acesso e a interação com o intuito de gerar ação contínua.

Nesse sentido, a fixação de crenças no contexto investigado pressupõe a conformação de uma dinâmica transmídia que aponta para o uso estratégico das plataformas digitais. Nesse cenário, a disputa entre crenças concorrentes opera por associação (experiência colateral) de argumentos, verdadeiros ou falsos, com o intuito de ressignificar crenças dominantes e, assim, alterar o curso da significação da notícia (semiose). Trata-se de uma dinâmica pragmática típica de ativismo transmídia porque busca conformar ações coletivas delineadas por aderência (inserindo a dúvida em crenças concorrentes), mobilização (buscando a fixação de crenças afins) e ativismo (por meio de hábitos coletivos de ação fundados em crenças tenazes) em conexões digitais. Paradoxalmente, a circulação em larga escala de conteúdos supostamente falsos favorece o escrutínio coletivo da dúvida e, consequentemente, o desenvolvimento de processos de verificação que atuam pragmaticamente no aprimoramento das notícias em sua busca deontológica pela verdade, de modo mais amplo.

\section{CONSIDERAÇÕES FINAIS}

A dinâmica transmídia de conteúdos noticiosos falsos ou distorcidos funda-se em processos sofisticados de engajamento social, os quais se expandem significativamente por experiência colateral, operação de sentido que adiciona informação à semiose com base em familiaridade prévia com o objeto que o signo denota. A notícia é entendida como processo de significação que busca alcançar recursivamente a realidade por meio do ideal normativo da verdade, cujo efeito prático será uma crença compartilhada na forma de opinião.

A concepção pragmática da verdade é um ideal normativo que baliza o desenvolvimento da semiose, não um atributo da notícia. Falsidade e veracidade são, 
portanto, operações de sentido que permeiam a semiose das notícias. Culminam em efeitos (interpretante) que representam a relação estabelecida pela notícia (signo) com suas referências (objeto) para mediar a formação de certa opinião (interpretante). A dúvida (natureza icônica) busca revisar uma crença estabelecida ou fixar crença concorrente por meio de verificação (natureza indicial), com vistas a produzir uma crença capaz de alcançar o estatuto de convenção social, ainda que arbitrária e relativamente provisória, na forma da designação simbólica de falsa ou verdadeira. A semiose das notícias desdobra-se transmidiaticamente, e tão mais amplo será seu alcance quanto mais firme for a crença que a delineia.

Contextos de polarização política favorecem a circulação transmídia de conteúdos noticiosos falsos ou distorcidos, razão pela qual se buscou observar a questão no âmbito do julgamento em segunda instância do ex-presidente Luiz Inácio Lula da Silva, realizado em 24 de janeiro de 2018. As interações registradas no Twitter, Facebook e Instagram em torno de notícias relacionadas a esse tema foram observadas mediante procedimentos de coleta manual e automática. Os resultados demonstraram que o engajamento social no cenário investigado foi impulsionado por componentes sígnicos, como associação a celebridades e uso de hashtags com conotação de polarização política, com o intuito de fixar crença por opinião compartilhada na forma de compartilhamento em larga escala nas conexões digitais. $\mathrm{O}$ estudo demonstra a capacidade agenciadora das notícias pretensamente falsas em contextos sociais marcados por forte polarização política, a despeito de evidências em contrário. Por outro lado, evidencia que a dinâmica transmídia de conteúdos noticiosos falsos ou distorcidos estimula a verificação de conteúdos, contribuindo para $\mathrm{o}$ aprimoramento dos processos de significação da notícia de modo mais amplo. $\mathbf{M}$

\section{REFERÊNCIAS}

Ahmed, K. (2017, 17 de fevereiro). Zuckerberg critica "bolhas" e polarização e lança manifesto para "reinicar globalização". BBC News Brasil. Recuperado de https://www.bbc.com/portuguese/salasocial-38988781

Allcott, H. \& Gentzkow, M. (2017). Social media and fake news in the 2016 election. Journal of Economic Perspectives, 31(2), 211-236. doi: 10.1257/jep.31.2.211

Alsina, R. (2005). A construção da notícia (J. A. Pierce, trad.). Petrópolis, RJ: Vozes. Alzamora, G. (2018). A semiotic approach to transmedia storytelling. In R. R. Gambarato \& M. Freeman (Orgs.), The Routledge Companion to Transmedia Studies (pp. 438-446). Londres, UK: Routledge.

Alzamora, G. \& Gambarato, R. (2014). Peircean semiotics and transmedia dynamics: Communicational potentiality of the model of semiosis. Ocula, 15(15), 1-15. doi: 10.12977/ocula29 
Alzamora, G. \& Andrade, L. (2016). A representação do Impeachment Day mediada por hashtags no Twitter e no Facebook: Semiose em redes híbridas. Revista Interin, 2(21), 100-121. Recuperado de http://bit.ly/2Wocmnq Alzamora, G. (2017, junho). Televisão em semiose: Mídia, intermídia, transmídia. Artigo apresentado no XXVI Encontro Anual da Compós, São Paulo, SP. Recuperado de https://bit.ly/2HIjiZ3

Balzac, H. (1991). Os jornalistas (J. Dmonech, Trad.). Rio de Janeiro, RJ: Ediouro. BBC. (2017, 21 de setembro). Fake internet contente a high concern, but apetite for regulation weakens: Global poll. $B B C$. Recuperado de: https://bit.ly/2VxpbvP

Bergman, M. (2010). C. S. Peirce on interpretation and collateral experience. Signs, 4, 134-161. Recuperado de https://tidsskrift.dk/signs/article/view/26855

Bertetti, P. (2014). Toward a typology of transmedia characters. International Journal of Communication, 8, 2344-2361. Recuperado de http://bit.ly/2J4hutf

Camponez, J. C. C. S. (2009). Fundamentos de deontologia do jornalismo: A auto-regulação frustrada dos jornalistas portugueses (1974-2007). (Tese de doutorado não publicada). Universidade de Coimbra, Portugal.

Colapietro, V. (2004). The routes of significance: Reflections on Peirce's Theory of Interpretantes. Cognitio, 5(1), 11-27. Recuperado de http://bit.ly/2vofTX3

Dahlgren, P. (2013). The political web: Media participation and alternative democracy. Basingstoke, UK: Palgrave Macmillan.

De Waal, C. (2007). Sobre pragmatismo (C. T. Rodrigues, Trad.). São Paulo, SP: Loyola.

Elleström, L. (2014). Media transformation: The transfer of media characteristics among media. Nova York, NY: Palgrave Macmillan.

Facebook. (2018, 24 de janeiro). Monitor do debate politico no meio digital. Facebook. Recuperado de http://bit.ly/2DAgUQj

Forum. (2018, 23 de janeiro). A maior manifestação da história de Porto Alegre: 70 mil pessoas com Lula. Forum. Recuperado de https://bit.ly/2SH087U

Gillespie, T. (2014). The relevance of algorithms. In T. Gillespie, P. J. Boczkowski, \& K. A. Foot (Eds.), Media technologies: Essays on communication, materiality, and society (pp. 167-193). Cambridge, MA: MIT Press.

Groshek, J., \& Groshek, M. C. (2013). Agenda Trending: Reciprocity and the predictive capacity of social network sites in intermedia agenda setting across issues over time. Media and Communication, 1(1), 15-27. doi: 10.2139/ ssrn.2199144

Igarza, R. (2010). Nuevas formas de consumo cultural: Por qué las redes sociales están ganando la batalla de lãs audiências. Comunicação, Mídia e Consumo, 7(20), 59-90. doi: 10.18568/cmc.v7i20.205

Hartshorne, C., \& Weiss, P. (Eds.). (1974). The collected papers of Charles Sanders Peirce (Vols. 1-6). Cambridge, MA: Harvard University Press. 
Jenkins, H. (2008). Cultura da convergência (S. Alexandria, Trad.). São Paulo, SP: Aleph.

Jenkins, H. (2009, 12 de dezembro). The revenge of the origami unicorn: Seven principles of transmedia storytelling. Henry Jenkins. Recuperado de http://bit.ly/2vmL9pG

Jenkins, H. (2010, 21 de junho). Transmedia education: The 7 Principles Revisited. Henry Jenkins. Recuperado de http://bit.ly/2ZwJZFK

Jenkins, H. (2016, 19 de janeiro). Telling stories: Lina Srivastava talks about transmedia activism (Part one). Henry Jenkins. Recuperado de https://bit.ly/2Ufzerx

Jenkins, H. (2017). Transmedia logics and locations. In B. W. L. D. Kurtz, \& M. Bourdaa. The rise of transtexts: Challenges and opportunities (pp. 220240). Nova York, NY: Routledge.

Jenkins, H., Green, J., \& Ford, J. (2014). Cultura da conexão: Criando valor e significação por meio de mídia propagável. São Paulo, SP: Aleph.

Ketner, K. L., \& Kloesel, C. J. W. (Orgs.). (1986). Peirce, semeiotic, and pragmatism: Essays by Max H. Fisch. Bloomington, IN: Indiana University Press.

Kinder, M. (1991). Playing with power in movies, television, and video games: From Muppet babies to Teenage Mutant Ninja Turtles. Berkeley, CA: University of California Press.

Lippmann, W. (2008). Opinião pública. Petrópolis, RJ: Vozes.

Lupa. (2018, 24 de janeiro). Julgamento de Lula: Chacamos as informações mais vistas nas redes. Uol. Recuperado de https://bit.ly/2WcLvLn

Martins, A. (2017, 17 de setembro). Na web, 12 milhões difundem fake news políticas. O Estado de S. Paulo. Recuperado de https://bit.ly/2xQAZ4L

Matsuki, E. (2018, 26 de Janeiro). Marieta Severo fez texto sobre Lula chamado "Os erros de Luís" \#boato. Boatos.org. Recuperado de http://bit.ly/2UTNBD8 Nöth, W. (1996). A semiótica no século XX. São Paulo, SP: AnnaBlume.

Peirce Edition Project (Ed.). (1998) The essential Peirce: Selected philosophical writings (1893-1913) (Vols. 1-2). Bloomington, IN: Indiana University Press.

Poell, T., \& van Dijck, J. (2015). Social media and activist communication. In C. Atton (Ed.), The Routledge Companion to Alternative and Community Media (pp. 527-537). Londres, UK: Routledge.

Ramonet, I. (2013). A explosão do jornalismo na era digital. In D. Moraes, I. Ramonet, \& P. Serrano (Orgs.), Mídia, poder e contrapoder: Da concentração monopolística à democratização da informação (pp. 85-102). São Paulo, SP: Boitempo.

Rodrigues, R. (2018, 29 de junho). Defesa admite que Lula cometeu crime no caso do triplex? Papo Tv. Recuperado de https://bit.ly/2CVhs3z 
Sanghvi, R. (2006, 5 de setembro). Facebook gets a Facelift. Facebook. Recuperado de http://bit.ly/2GKbnHQ

Santaella, L. (1992). A assinatura das coisas: Peirce e a literatura. Rio de Janeiro, RJ: Imago.

Sarlo, B. (2011, $1^{\circ}$ de junho). O animal político na web. Serrote. Recuperado de https://www.revistaserrote.com.br/2011/06/o-animal-politico-na-web/

Scolari, C. (2009). Transmedia story telling: Implicit consumers, narrative worlds, and branding in contemporary media production. International Journal of Communication, 3, 586-606. Recuperado de http://bit.ly/2UQhIGH

Shook, J. (2002). Os pioneiros do pragmatismo americano (F. M. Said, Trad.). Rio de Janeiro, RJ: DP\&A.

Silverman, C., Lytvynenko, J., \& Pham, S. (2017, Dezembro 28). These are 50 of the biggest fake news hits on Facebook in 2017. BuzzFeedNews. Recuperado de https://bit.ly/2PtXGAF

Soriano, C. (2016). Transmedia mobilization: Agency and literacy in minority productions in the age of spreadable media. The Information Society, 32(5), 354-363. doi: 10.1080/01972243.2016.1212620

Srivastava, L. (2009, 4 de março). Transmedia activism: Telling your story across media platforms to create effective social change. Namac. Recuperado de http://bit.ly/2IVWULr

The Guardian. (2017, 1 de novembro). Fake news is "very real" word of the year for 2017. The Guardian. Recuperado de https://bit.ly/2iTWYk4

Traquina, N. (2005). Teorias do Jornalismo: Porque as notícias são como são (Vol. 1). Florianópolis, SC: Insular.

Uscinski, J., \& Butler, R. (2013). The epistemology of fact checking. Critical Review, 25(2), 162-180. doi: 10.1080/08913811.2013.843872

Vieira, V. (2013, maio). O papel da comunicação digital na Primavera Árabe: Apropriação e mobilização social. Artigo apresentado no V Congresso da Compolítica, Curitiba, PR. Recuperado de https://bit.ly/2VOTDRU

Wardle, C. \& Derakhshan, H. (2017). Information disorder: Toward an interdisciplinary framework for research and policy making. Council of Europe Report. Recuperado de https://bit.ly/2V3Y62S

Artigo recebido em 29 de agosto de 2018 e aprovado em 6 de fevereiro de 2019. 